\title{
Recipient Outcomes with Younger Donors Undergoing Living Donor Liver Transplantation
}

Faisal S. Dar ${ }^{1}$, Nusrat Y. Khan ${ }^{1}$, Rubab Ali ${ }^{1}$, Hamzah Khawar. Khokhar ${ }^{2}$, Haseeb H. Zia ${ }^{1}$, Abu Bakar H. Bhatti ${ }^{1}$, Najmul H. Shah ${ }^{1}$

1. Surgery, Shifa International Hospital, Islamabad, PAK 2. Surgery, Shifa International Hospital, Islamabad, PAK

$\square$ Corresponding author: Abu Bakar H. Bhatti, abubakar.hafeez@yahoo.com

\section{Abstract \\ Introduction}

The impact of donor age on liver transplantation is well known. Data on an appropriate donor age cut-off for living donor liver transplantation (LDLT) with a background of hepatitis C (HCV) is generally limited. The objective of this study was to determine whether limiting donor age to less than 35 years improved outcomes in patients with HCV-related end-stage liver disease (ESLD).

\section{Methods}

This was a retrospective review of 169 patients who underwent LDLT for HCV-related ESLD. The patients were divided into two groups based on whether they received grafts from donors $\leqslant 35$ (Group 1) or > 35 (Group 2) years of age. Kaplan Meier curves were used to determine survival. Uni and multivariate analysis were performed to determine independent predictors of mortality.

\section{Results}

Mean donor age was $25.1 \pm 5.2$ and $40.1 \pm 3.4$ years $(\mathrm{P}<0.0001)$. Early allograft dysfunction (EAD) was seen in $11.7 \%$ patients in Group 1 versus $29.6 \%$ in Group $2(\mathrm{P}=0.02)$. A significant difference in mortality was present between the two groups, i.e., $33.3 \%$ versus $15.8 \%(\mathrm{P}=0.04)$. The estimated four-year overall survival (OS) was 78\% and 64\% (P=0.03). Upon doing univariate analysis, the donor age $(\mathrm{P}=0.04)$ and $\operatorname{EAD}(\mathrm{P}=0.006)$ were found to be significant variables for mortality. On multivariate analysis, EAD was the only independent predictor of mortality (Hazard ratio: 2.6; confidence interval: 1.1 - 5.8; $\mathrm{P}=0.01$ ).

Received 01/30/2019

Review began 02/22/2019 Review ended 02/25/2019 Published 03/04/2019

(c) Copyright 2019

Dar et al. This is an open access article distributed under the terms of the Creative Commons Attribution License CC-BY 3.0., which permits unrestricted use, distribution, and reproduction in any medium, provided the original author and source are credited.

\section{Conclusion}

Opting for younger donors ( $\leqslant 35$ years) for HCV-related ESLD patients lowers the risk of EAD and improves overall survival.

Categories: Transplantation

Keywords: liver transplantation, donors, mortality, allograft dysfunction

Introduction 
Living donor liver transplantation (LDLT) is an invaluable therapeutic modality in regions with deceased donor organ shortage [1]. Several donor and recipient factors impact outcomes after transplantation and donor age is one of them [2-3]. Donor risk index (DRI) is a widely used criterion that utilizes various donor characteristics to stratify the risk of post-transplant graft loss [4]. Other than donor age and height, none of the DRI variables are applicable to the LDLT setting. The literature on the appropriate donor age cut-off for LDLT with background hepatitis $\mathrm{C}$ virus (HCV) is generally limited [5]. Moreover, in the presence of HCV, which has been linked with a higher rate of graft failure and mortality, the evidence is lacking regarding an appropriate age cut-off [6]. After age 30, there is a progressive loss of liver volume and blood flow. These changes lead to the progressive deterioration of the liver's response to situations with high metabolic demands [7-9]. It has been shown that in adult LDLT, a mean donor age of 34.4 years is protective against early graft dysfunction versus an age of 43.1 years [10].

We have been very cautious in our donor selection in terms of donor age compared to other programs [11]. The age cut-off used at our center is 18-45 years. Despite this age cut-off, we have experienced biliary complications, HCV recurrence, early allograft dysfunction (EAD), and mortality in some patients. Would a younger donor age cut off ( $\leqslant 35$ years) confer any outcome benefit for patients undergoing LDLT for HCV-related end-stage liver disease (ESLD)? The objective of this study was to determine if donor age $<35$ years improves outcomes in transplanted patients with a HCV-positive ESLD.

\section{Materials And Methods}

This was a retrospective review of patients who underwent LDLT. Until April 2016, 303 LDLTs were performed at the Shifa International Hospital, Islamabad. A total of 169 patients who underwent LDLT for HCV-related ESLD were included in the study. Patients with acute liver failure, age less than 18 years, dual graft, domino recipient, and those transplanted after 30th October 2015 were excluded.

The details of the donor and recipient evaluations and selection have been reported elsewhere $[1,12]$. Donors were $18-45$ years of age, blood group compatible, and related to recipients. The decision to transplant was made after receiving approval from the Human Organ and Tissue Transplant Authority (HOTA) of Pakistan and a transplant listing meeting.

The donor/recipient characteristics and operative variables were assessed. For this study, the patients were divided into two groups based on donor age; Group 1 had grafts from donors aged 35 years and below and Group 2 had donors aged 36 years and above. Donor characteristics were compared between the two groups including gender, body mass index (BMI), and graft and operative variables. A comparison was also made for recipient characteristics including age, gender, BMI, child Turcot Pugh score (CTP) score, model for end-stage liver disease (MELD) score, the presence of hepatocellular carcinoma (HCC), and operative variables. In terms of outcomes, the following variables were assessed; 1) early allograft dysfunction (EAD); 2) HCV recurrence; 3) biliary complications; 4) 90-day mortality; 5) overall mortality. Biliary complications were categorized based upon Clavien Dindo grading [13]. EAD was defined as the presence of one or more of the following: Bilirubin $\geqslant 10 \mathrm{mg} / \mathrm{dl}$ on Day 7 , international normalized ratio (INR) $\geqslant 1.6$ on Day 7 , and alanine or aspartate aminotransferase $>2,000 \mathrm{IU} / \mathrm{L}$ within the first seven days after liver transplantation [14]. HCV recurrence was defined as a positive polymerase chain reaction (PCR) in the presence of rising liver function tests (LFTs).

For categorical variables, the Chi-Square test and the Fisher exact test were used, while for interval variables, independent tests were applied. For survival, Kaplan Meier curves were generated, and log rank tests were used to determine significance. Overall survival was calculated by subtracting date of death/last follow up from date of transplant. A Cox proportional hazard model was used to determine independent predictors of patient 


\section{Cureus}

survival. Variables with a P-value $<0.1$ were considered for univariate analysis and significant variables $(\mathrm{P}<0.05)$ on univariate analysis were included in the multivariate analysis. All analysis was performed on Statistical Package for Social Sciences (SPSS) version 20 (IBM, Armonk, New York, United States). The study was approved by the hospital ethics committee.

\section{Results}

\section{Donor and recipient characteristics}

Table 1 demonstrates various donor and recipient variables. Majority of donors in Group 1 were males, i.e., 109 (75.1\%) versus $12(50 \%)(\mathrm{P}=0.01)$. Mean donor age was $25.1 \pm 5.2$ and $40.1 \pm 3.4$ years $(\mathrm{P}<0.0001)$. Mean donor BMI was $23.9 \pm 3.8$ and $27.3 \pm 3.2 \mathrm{Kg} / \mathrm{m} 2$ for the two groups $(\mathrm{P}<$ $0.0001)$. Mean LAI was $11 \pm 5.9$ and $9.8 \pm 5.3(\mathrm{P}=0.3)$. Mean recipient age was $48.6 \pm 8.1$ and $45.6 \pm 7.6$ years $(\mathrm{P}=0.1)$. Mean recipient $\mathrm{BMI}$ was $24 \pm 3.7$ and $23.9 \pm 3.8 \mathrm{Kg} / \mathrm{M} 2(\mathrm{P}=0.7)$. Mean MELD score was $17.2 \pm 6.1$ and $16.9 \pm 7.9(\mathrm{P}=0.7)$. Mean cold ischemia time was $47.4 \pm 29.9$ and $37 \pm 21.4$ minutes $(\mathrm{P}=0.1)$.

Donor characteristics

Lobe

Middle hepatic vein used

Arterial anatomy

Biliary anatomy

Recipient characteristics

Gender

Child Turcot Pugh grade

Hepatocellular carcinoma

\section{Group 1 N=145}

Number Percent

Male

109

Female

Right

Left

Yes

34

Standard

Standard

92

56

Male

119

Female

26

A

B

C

Present

75.1

24.9

97.9

2.1

23.4

63.4

38.6

18

37

9

\section{Group 2 N=24}

Number Percent

$P$ value

12

50

$0.01^{*}$

50

95.8

0.4

4.2

8.3

0.09

5.8

0.1

9

21

87.5

0.3

12.5

$4.8 \quad 2$

8.3

0.6

$\begin{array}{lll}40.7 & 8 & 33.4\end{array}$

$\begin{array}{lll}54.5 & 14 & 58.3\end{array}$

58.3

$25.5-7$

7

29.1

0.8

\section{TABLE 1: Donor and recipient characteristics of the study cohort}

\section{Comparison of outcomes}

No significant differences were observed between the two groups in terms of biliary 


\section{Cureus}

complications and HCV recurrence. There was a statistically significant difference in EAD and overall mortality as shown in Table 2 . EAD was seen in $11.7 \%$ of the patients in Group 1 versus $29.6 \%$ in Group $2(\mathrm{P}=0.02)$. Overall, the mortality was significantly high in Group 2 patients, i.e., $33.3 \%$ versus $15.8 \%(\mathrm{P}=0.04)$. Since there was a significant difference in the gender distribution between the two groups as shown in Table 1, the impact of gender on EAD and mortality was separately assessed in Group 1 patients. Overall mortality for males and females was $17.4 \%(19 / 109)$ versus $11.1 \%(4 / 36)$ and was not significantly different $(\mathrm{P}=0.4)$.

\begin{tabular}{|c|c|c|c|c|c|}
\hline & \multicolumn{2}{|c|}{ Group 1 N=145 } & \multicolumn{2}{|c|}{ Group 2 N=24 } & \multirow[b]{2}{*}{$P$ value } \\
\hline & Number & Percent & Number & Percent & \\
\hline Hepatitis C virus recurrence & 54 & 37.2 & 9 & 37.5 & 0.9 \\
\hline Early allograft dysfunction & 17 & 11.7 & 1 & 29.1 & $0.02^{*}$ \\
\hline Bılıary complicatıons & 30 & 20.6 & 6 & 25 & 0.6 \\
\hline 90 day mortality & 13 & 8.9 & 5 & 20.8 & 0.08 \\
\hline Overall Mortality & 23 & 15.8 & 8 & 33.3 & $0.04^{*}$ \\
\hline
\end{tabular}

TABLE 2: Comparison of outcomes between the two groups

\section{Predictors of survival}

Estimated one-year overall survival (OS) for the whole group was 87\%. Estimated one-year OS for Groups 1 and 2 were 88\% and 71\% and estimated four-years OS were 78\% and 64\% and was significantly different $(\mathrm{P}=0.03$ ) (Figure 1). We included gender, BMI, and MHV use in our univariate analysis for mortality as shown in Table 3. On multivariate analysis, EAD was the only independent predictor of survival and resulted in a significant increase in the risk of death [HR: 2.6; CI: $1.1-5.8 ; \mathrm{P}=0.01]$. There was a major reduction in risk of death posttransplantation in the group with donors $<35$ years age secondary to lower rates of EAD. 


\section{Cureus}

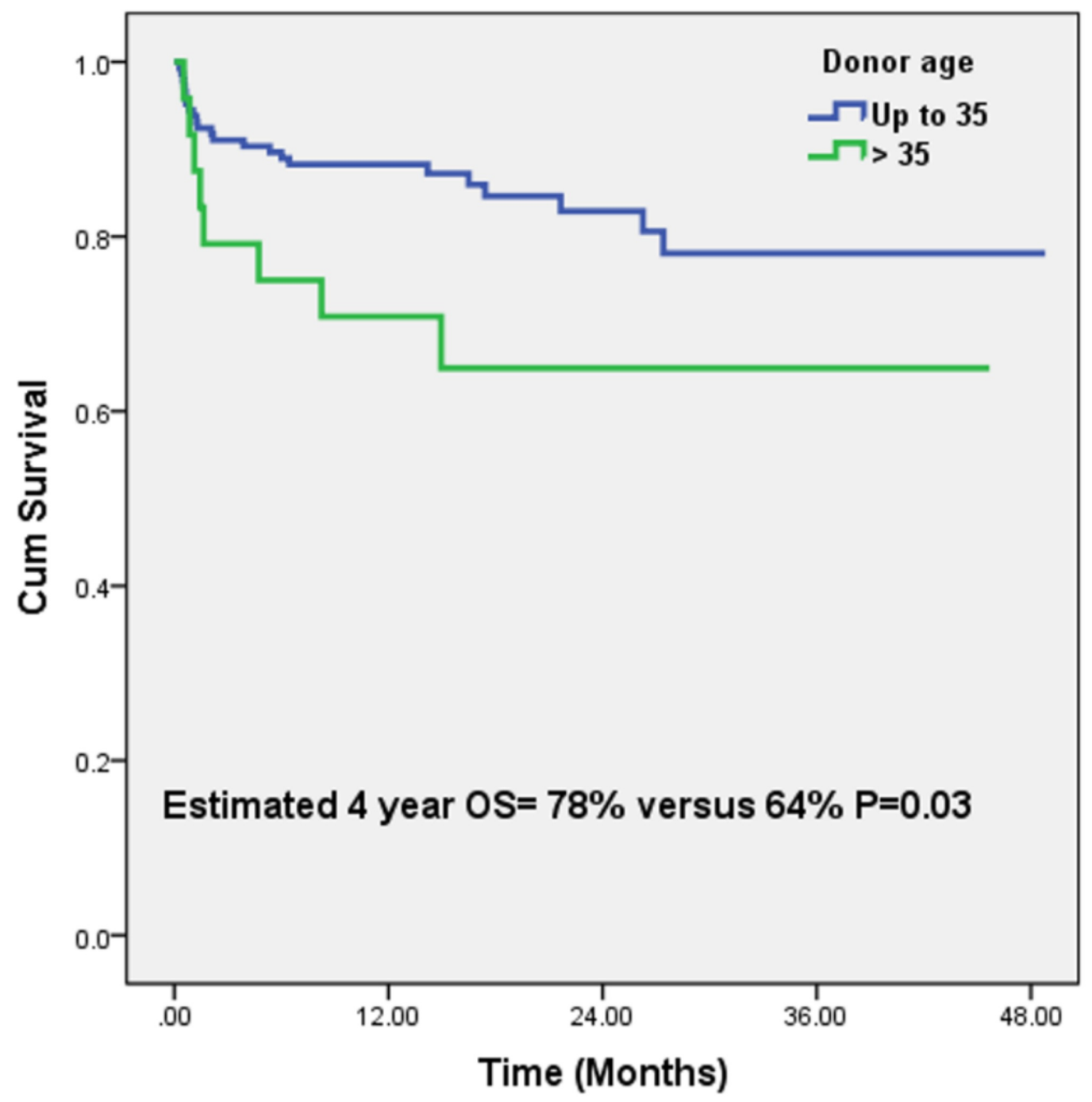

FIGURE 1: Estimated four-year overall survival in patients with HCV related end-stage liver disease with donor age cut-off of 35 years

HCV: hepatitis $\mathrm{C}$ virus 


\section{Cureus}

\section{Variables}

Univariate analysis

Mortality

1) Male gender

Female

2) Body mass index $\leq 25$

$>25$

3) Middle hepatic vein used

Not used

4) Early allograft dysfunction present

Absent

5) Donor age $\leq 35$

$>35$

Multivariate analysis

Mortality

1) Early allograft dysfunction present

absent

2) Donor age $\leq 35$

Age $>35$

\section{Hazard ratio}

$95 \%$ confidence interval

$P$ value

.4

$0.6-3.2$

0.4

1

1

0.9-1.1

0.8

1

1.03

0.6-1.6

0.8

1

0.33

$0.1-0.7$

$0.006^{*}$

1

0.4

0.1-0.9

$0.04^{*}$

1

2.6

$1.1-5.8$

$0.01^{*}$

1

0.5

$0.2-1.1$

0.1

TABLE 3: Univariate and multivariate analysis for post transplant mortality

\section{Discussion}

The current study demonstrates the outcomes of LDLT recipients for HCV-related ESLD. Donors were younger with a male predilection and the majority of patients were CTP grade $C$ at the time of transplantation. Younger donor age ( $\leqslant 35$ years) conferred survival advantage secondary to the lower rates of EAD. Variable donor age cut-offs have been used in different studies. This represents differences in the unique genetic makeup of the individual population, etiology of liver failure, and DDLT versus LDLT [15-18]. A number of studies have addressed donor ages in LDLT [16-21]. The outcomes remain variable with some studies demonstrating an inferior recipient survival and increased frequency of small for size syndrome, while others show no impact on outcomes. Han and colleagues compared recipient outcomes in 604 LDLTs and found that a donor age cut-off of 55 years to be associated with increased recipient mortality [11]. On the other hand, Li and colleagues in their study on 129 LDLTs demonstrated acceptable and comparable survival with donors greater than or lesser than 70 years of age [18]. Ikegami and colleagues demonstrated a higher rate of small for size syndrome with donors older than 50 years [19]. There is no literature on LDLT that solely demonstrates the impact of having a younger donor age ( $\leqslant 35$ years) in HCV-positive recipients. In the current study, $169 \mathrm{HCV}$ related ESLD recipients were included, and a relatively younger donor age compared to other 
studies was found to significantly impact the EAD and, thus, mortality.

Several prognostic factors have been proposed to identify the risk factors for graft loss after transplantation [4]. Important factors like cold ischemia time (CIT), cause of death, allocation system, and race are not relevant to LDLT since the CIT time is short in LDLT, all donors are alive, and allocation is not required since patients do not compete for organs in the presence of individualized donations. Other factors including recipient age, BMI, CTP, and MELD score were evenly distributed in the two groups.

The current study demonstrates superior survival with donors $\leqslant 35$ years in a relatively younger donor cohort (maximum age 45 years). The rate of biliary complications in our cohort was similar between the two groups probably because biliary complications have been associated with relatively older and extended criteria donors [22]. Donor age has been associated with EAD, and it was the only significant variable on univariate analysis in the current study [23]. No significant difference in HCV recurrence was observed in the current study. A majority of the deaths occurred within the first 90 days after transplantation and were attributable to sepsis which itself can be a sequel of EAD [23]. HCV genotype 3 is the predominant genotype in the subcontinent. It has been associated with an increased rate of fibrosis and a higher incidence of HCC [24]. Furthermore, the response to direct acting anti-viral (DAA) medications is still not well understood, but genotype 3 has been associated with a lower response rate than other genotypes [25]. A relatively short follow-up and frequent use of DAAs might have a plausible role in the current study with very few mortalities attributable to HCV recurrence.

Without much impact on other outcome variables, the younger donor age had a significant impact on the overall survival of transplanted patients. Donor gender and BMI were the only variables that were unevenly distributed between the two groups but did not impact survival on univariate analysis. In order to confirm the impact of gender, we also looked for the genderspecific rate of EAD and mortality in recipients of grafts $\leqslant 35$ years of age and found no significant difference. Several mechanisms have been proposed to explain changes in liver architecture with increasing age. Perhaps the most widely understood is telomere shortening, which is most active in the 30s [26-27]. Similarly, it has been shown that a mean age of 34.4 years might be protective for EAD for reasons yet unknown. The limitations of the current study include its retrospective design and the smaller number of younger donors. However, considering that donors $<35$ years of age represent a very select group of donors, it still represents a significant number.

The current study identified EAD as an independent predictor of mortality and was seen more frequently in an older donor age ( $>35$ years). The Survival for patients who received grafts from younger donors was $88 \%$ versus $71 \%$ at one year. Clearly, one-year survival of $71 \%$ is below the international average, but an overall one-year survival of $87 \%$ for HCV-related ESLD is very much in line with international recommendations [28].

\section{Conclusions}

The current study demonstrates a major reduction in the risk of death post-transplantation in the group with donors $<35$ years age secondary to lower rates of EAD. The ideal donor age cutoff remains debatable due to the interplay of multiple donor, recipient, and treatment-related variables that impact graft dysfunction. It is unclear if larger studies with longer follow-up can better answer this question, but they can definitely enhance our understanding of this important variable and how it relates to patient outcomes.

\section{Additional Information Disclosures}


Human subjects: Consent was obtained by all participants in this study. Shifa International Hospital, ERC issued approval N/A. The hospital ethics committee granted exemption from formal review of this study. . Animal subjects: All authors have confirmed that this study did not involve animal subjects or tissue. Conflicts of interest: In compliance with the ICMJE uniform disclosure form, all authors declare the following: Payment/services info: All authors have declared that no financial support was received from any organization for the submitted work. Financial relationships: All authors have declared that they have no financial relationships at present or within the previous three years with any organizations that might have an interest in the submitted work. Intellectual property info: This study was accepted for poster presentation in the Annual Meeting of the Americas Hepato-Pancreato-Biliary Association, held on March 29 - April 2, 2017 at Miami Beach, FL and was later published as an abstract in HPB journal. Bhatti AH, Dar FS, Ali R, et al. Outcomes with donors aged $<35$ years in living donor liver transplantation for hepatitis C. HPB , Volume 19, S128 https://doi.org/10.1016/j.hpb.2017.02.286 2017. Other relationships: All authors have declared that there are no other relationships or activities that could appear to have influenced the submitted work.

\section{References}

1. Dar FS, Bhatti AB, Dogar AW, et al.: The travails of setting up a living donor liver transplant program: experience from Pakistan and lessons learned. Liver Transpl. 2015, 21:982-990. 10.1002/1t.24151

2. John RL, Jolene SS, Bettina JS, Alice HC, Robert DG, Russell HW: Differential effects of donor age in liver transplant recipients infected with hepatitis $B$, hepatitis $C$ and without viral hepatitis. Am J Transplant. 2005, 5:549-557. 10.1111/j.1600-6143.2005.00741.x

3. Bertuzzo VR, Cescon M, Odaldi F, et al.: Actual risk of using very aged donors for unselected liver transplant candidates: A European single-center experience in the MELD era. Ann Surg. 2016, 265:388-396. 10.1097/SLA.0000000000001681

4. Feng S, Goodrich NP, Bragg-Gresham JL, et al.: Characteristics associated with liver graft failure: the concept of a donor risk index. Am J Transplant. 2006, 6:783-790. 10.1111/j.16006143.2006.01242.x

5. Lué A, Solanas E, Baptista $\mathrm{P}$, et al.: How important is donor age in liver transplantation? . World J Gastroenterol. 2016, 22:4966-4976. 10.3748/wjg.v22.i21.4966

6. Regev A, Schiff ER: Liver disease in the elderly . Gastroenterol Clin North Am. 2001, 30:547563. 10.1016/S0889-8553(05)70195-3

7. Wynne HA, Cope LH, Mutch E, Rawlins MD, Woodhouse KW, James OF: The effect of age upon liver volume and apparent liver blood flow in healthy man. Hepatology. 1989, 9:297-301. 10.1002/hep.1840090222

8. James OF: Gastrointestinal and liver function of old age. Clin Gastroenterol. 1983, 12:671-691.

9. Wynne HA, James OF: The ageing liver. Age Ageing. 1990, 19:1-3.

10. Sanefuji K, Iguchi T, Ueda S, et al.: New prediction factors of small for size syndrome in living adult liver transplantation for chronic liver disease. Transplant Int. 2010, 23:350-357.

10.1111/j.1432-2277.2009.00985.x

11. Han JH, You YK, Na GH, et al.: Outcomes of living donor liver transplantation using elderly donors. Ann Surg Treat Res. 2014, 86:184-191. 10.4174/astr.2014.86.4.184

12. Dar FS, Zia H, Hafeez Bhatti AB, et al.: Short-term donor outcomes after hepatectomy in living donor liver transplantation. J Coll Physicians Surg Pak. 2016, 26:272-276.

13. Clavien PA, Barkun J, de Oliveira ML, et al.: The Clavien-Dindo classification of surgical complications: five-year experience. Ann Surg. 2009, 250:187-196.

10.1097/SLA.0b013e3181b13ca2

14. Olthoff KM, Kulik L, Samstein B, et al.: Validation of a current definition of early allograft dysfunction in liver transplant recipients and analysis of risk factors. Liver Transpl. 2010, 16:943-949.

15. Adam R, Karam V, Delvart V, et al.: Evolution of indications and results of liver transplantation in Europe. A report from the european liver transplant registry (ELTR).. J Hepatol. 2012, 57:675-688. 10.1016/j.jhep.2012.04.015 
16. Reese PP, Sonawane SB, Thomasson A, Yeh H, Markmann JF: Donor age and cold ischemia interact to produce inferior 90-day liver allograft survival. Transplantation. 2008, 85:17371744. 10.1097/TP.0b013e3181722f75

17. Uchiyama H, Shirabe K, Kimura K, et al.: Outcomes of adult-to-adult living donor liver transplantation in 321 recipients. Liver Transpl. 2016, 22:305-315. 10.1002/1t.24378

18. Li C, Wen TF, Yan LN, et al.: Safety of living donor liver transplantation using older donors . J Surg Res. 2012, 178:982-987. 10.1016/j.jss.2012.06.065

19. Ikegami T, Taketomi A, Ohta R, et al.: Donor age in living donor liver transplantation . Transplant Proc. 2008, 40:1471-1475. 10.1016/j.transproceed.2008.02.084

20. Ikegami T, Nishizaki T, Yanaga K, et al.: The impact of donor age on living donor liver transplantation. Transplantation. 2000, 70:1703-1707.

21. Ono Y, Kawachi S, Hayashida T, et al.: The influence of donor age on liver regeneration and hepatic progenitor cell populations. Surgery. 2011, 150:154-161. doi: 10.1016/j.surg.2011.05.004.

22. Thorsen T, Aandahl EM, Bennet W, et al.: Transplantation with livers from deceased donors older than 75 years. Transplantation. 2015, 99:2534-2542. 10.1097/TP.0000000000000728

23. Graham JA, Samstein B, Emond JC. : Early graft dysfunction in living donor liver transplantation and the small for size syndrome. Curr Transp. 2014, 1:43-52. 10.1007/s40472013-0006-1

24. Kanwal F, Kramer JR, Ilyas J, Duan Z, El-Serag HB: HCV genotype 3 is associated with an increased risk of cirrhosis and hepatocellular cancer in a national sample of U.S. Veterans with HCV. Hepatology. 2014, 60:98-105.

25. Vasudevan S, Shalimar, Kavimandan A, et al.: Demographic profile, host, disease \& viral predictive factors of response in patients with chronic hepatitis $\mathrm{C}$ virus infection at a tertiary care hospital in north India. Indian J Med Res. 2016, 143:331-340.

26. Aini W, Miyagawa-Hayashino A, Tsuruyama T, et al.: Telomere shortening and karyotypic alterations in hepatocytes in long-term transplanted human liver allografts. Transpl Int. 2012, 25:956-966.

27. Takubo K, Nakamura K, Izumiyama N, et al.: Telomere shortening with aging in human liver. J Gerontol A Biol Sci Med Sci. 2000, 55:B533-B536. 10.1093/gerona/55.11.B533

28. Kim WR, Stock PG, Smith JM, et al.: OPTN/SRTR 2011 Annual Data Report ( 2013): Liver . Am J Transplant. 2013, 1:73-102. 